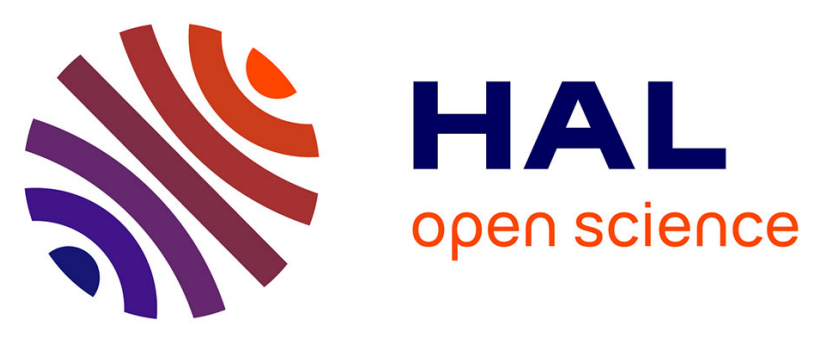

\title{
Access to Functionalized 3,5-Disubstituted 1,2-Dioxolanes under Mild Conditions through Indium(III) Chloride/Trimethylsilyl Chloride or Scandium(III) Triflate Catalysis
}

Alexis Pinet, Bruno Figadère, Laurent Ferrié

\section{To cite this version:}

Alexis Pinet, Bruno Figadère, Laurent Ferrié. Access to Functionalized 3,5-Disubstituted 1,2Dioxolanes under Mild Conditions through Indium(III) Chloride/Trimethylsilyl Chloride or Scandium(III) Triflate Catalysis. Advanced Synthesis and Catalysis, 2020, 362 (5), pp.1190-1194. 10.1002/adsc.201901145 . hal-02973069

\section{HAL Id: hal-02973069 \\ https://hal.science/hal-02973069}

Submitted on 20 Oct 2020

HAL is a multi-disciplinary open access archive for the deposit and dissemination of scientific research documents, whether they are published or not. The documents may come from teaching and research institutions in France or abroad, or from public or private research centers.
L'archive ouverte pluridisciplinaire HAL, est destinée au dépôt et à la diffusion de documents scientifiques de niveau recherche, publiés ou non, émanant des établissements d'enseignement et de recherche français ou étrangers, des laboratoires publics ou privés. 


\title{
Access to Functionalized 3,5-Disubstituted 1,2-Dioxolanes under Mild Conditions through Indium(III) Chloride/Trimethylsilyl Chloride or Scandium(III) Triflate Catalysis
}

\author{
Alexis Pinet ${ }^{\mathrm{a}}$, Bruno Figadère $^{\mathrm{a}}$ and Laurent Ferrié ${ }^{*^{\mathrm{a}}}$ \\ a BioCIS, Université Paris-Sud, CNRS, Université Paris-Saclay, Châtenay-Malabry 92290, France \\ E-mail : laurent.ferrie@u-psud.fr
}

Received: ((will be filled in by the editorial staff))

Supporting information for this article is available on the WWW under http://dx.doi.org/10.1002/adsc.201\#\#\#\#\#.

\begin{abstract}
Herein we report the use of catalytic amount of scandium(III) triflate or indium(III) chloride (with trimethylsilyl chloride) for the functionalization of endoperoxyacetals through Sakurai or Mukaiyama reactions. These catalysts allow milder and more practical conditions than those previously reported with improvements in scope and reproducibility. This method allows a full catalytic sequence from cyclopropanols to produce desired functionalized 1,2-dioxolanes.
\end{abstract}

Keywords: Peroxides; Peroxycarbenium; Acetal; Rareearths; Indium

Endoperoxides are a rich source of natural or unnatural bioactive products, leading to the development of important anti-malarial drugs such as Artemisinin or Arterolane. We were involved these last years in a scientific program towards the total synthesis of mycangimycin, a fatty acid containing a 1,2-dioxolane pattern (Figure 1). ${ }^{[1][2]}$

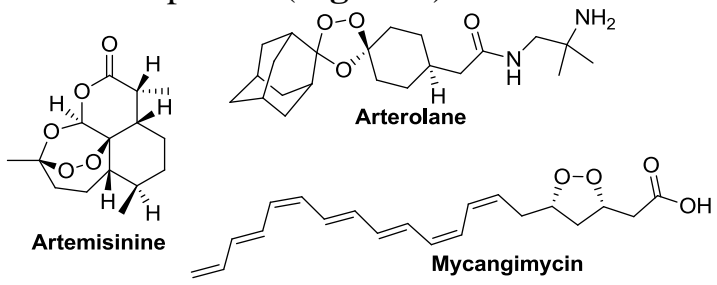

Figure 1. Artemisinin, Arterolan and Mycangimycin.

Thereafter, we described a methodology ${ }^{[3]}$ to build disubstituted 1,2-dioxolanes through Lewis acid activation of 1,2-dioxolanyl acetates with $\mathrm{TiCl}_{4}$ or $\mathrm{SnCl}_{4}$ at low temperature. The corresponding peroxycarbenium species ${ }^{[4]}$ was then trapped with a neutral nucleophile such as an allylsilane or silyl enol ether. We also highlighted the fact that the 1,2dioxolane moiety undergoes two paths of degradation/rearrangement due to activation by strong Lewis acids (mainly $\mathrm{TiCl}_{4}$ ), leading to lower yields but often higher diastereoselectivities. ${ }^{[3]}$ Moreover, this methodology tends to be difficult to control since a slight modification of the Lewis acid stoichiometry can lead to more degradation products (if in excess) or a worse conversion in desired product (if in deficiency), which gives sometimes difficulties to reproduce the experiments. ${ }^{[3]}$ Thus, the utilization of a mild Lewis acid under catalytic amount at room temperature would be highly desirable to circumvent the degradations products and the utilization of sub-stoichiometric amount of Lewis acid under low temperature conditions.

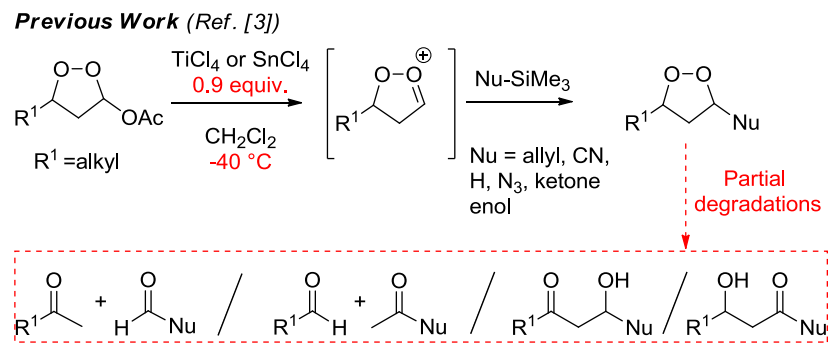

This Work

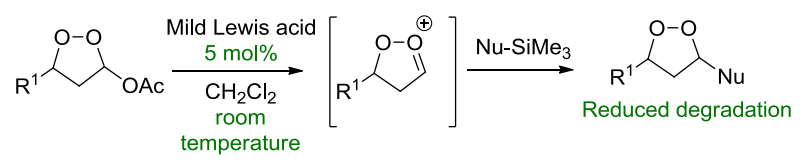

Scheme 1. Previous work about the synthesis of disubstituted 1,2-dioxolanes.

In order to prepare the dioxolanyl acetate, we transformed some cyclopropanols 1a-g (obtained either from Kulinkovich reaction ${ }^{[5]}$ or chromium (II) mediated cyclization of $\beta$-methylene aldehydes ${ }^{[6]}$ ) with two catalytic transformations. Firstly cyclopropanols 1a-g were oxidized to peroxyhemiacetals 2a-g through the formation of a hydroxyl radical mediated by $\mathrm{Mn}(\mathrm{acac})_{3}$, followed by cyclopropyl opening and trapping of intermediate radical with triplet oxygen. ${ }^{[7]}$ Peroxy-hemiacetals 2ag were then acetylated with acetic anhydride in the presence of $10 \mathrm{~mol} \%$ of $\mathrm{Yb}(\mathrm{OTf})_{3}$ to give acetoxyendoperoxyacetals 3a-g in overall good yields (Scheme 2). Noteworthy is that only $0.5 \mathrm{~mol} \%$ of $\mathrm{Yb}(\mathrm{OTf})_{3}$ was found, more recently, to be enough for the transformation. The use of a Lewis acid catalysed 
acetylation $^{[8]}$ was crucial to the success of this transformation since organic peroxides are reacting with amines, which are used in more common protocols. Both reactions are safe and multi-gram scalable and require low amounts of inexpensive catalysts.

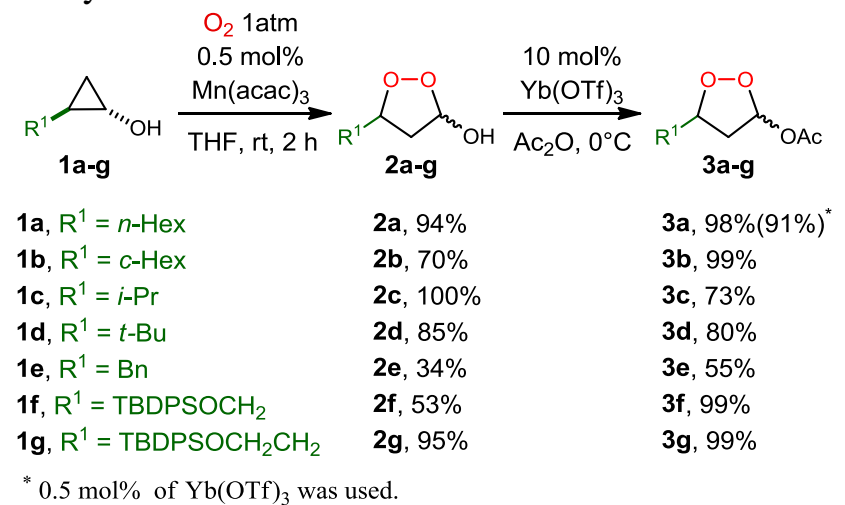

Scheme 2. Synthesis of 1,2-dioxolanyl acetates 3a-g

Then, our attention focused on the functionalization of endoperoxyacetals 3a-g under catalytic conditions. Considering the literature about catalytic Sakurai reactions combining $\mathrm{InCl}_{3}$ and TMSCl,${ }^{[9]}$ these reagents were chosen as a starting point. In the Sakurai reaction between peroxyacetal 3a and allyl-trimethylsilane $\mathbf{5}, \mathrm{InCl}_{3}$ or $\mathrm{TMSCl}$ were alone unable to catalyse the reaction (Table 1 entries 1 and 2). However, when the experiment was run with $10 \mathrm{~mol} \%$ of $\mathrm{InCl}_{3}$ and TMSCl (Table 1 entry 3 ), we obtained expected product $\mathbf{4 a}$ in less than 30 min. The amount of both TMSCl and $\mathrm{InCl}_{3}$ was then reduced gradually until reaching $0.5 \mathrm{~mol} \%$ of $\mathrm{InCl}_{3}$ (entry 6). The less the amount of $\mathrm{InCl}_{3}$ was used, the more the reaction time increased, but this shows the possibility to decrease sensibly the amount of catalyst (entries 5 and 6). Optimal conditions were identified for $5 \mathrm{~mol} \%$ of $\mathrm{InCl}_{3}$ and 2.5 equivalent of TMSCl (entry 4). This last result was comparable in term of yield and diastereoselectivity with the use of substoechiometric amount of $\mathrm{SnCl}_{4}$ at $-40{ }^{\circ} \mathrm{C}(81 \%$ vs $80 \%$ and $70: 30$ vs $65: 35){ }^{[3]}$

Table 1. Sakurai reaction study with $\mathrm{InCl}_{3} / \mathrm{TMSCl}$ as catalyst couple on peroxyacetal $\mathbf{3 a}$.

\begin{tabular}{|c|c|c|c|c|c|}
\hline Entry ${ }^{[a]}$ & Conditions & $\begin{array}{l}\text { Stoichio- } \\
\text { metry } \\
\text { (equiv) }\end{array}$ & $\begin{array}{l}\text { Reaction } \\
\text { Time }\end{array}$ & Yield $^{[\mathrm{a}]}$ & $\begin{array}{c}\mathrm{dr}^{[\mathrm{b}]} \\
\text { trans:cis }\end{array}$ \\
\hline 1 & $\mathrm{InCl}_{3}$ & 0.1 & $3 \mathrm{~h}$ & n.r. & / \\
\hline 2 & TMSCl & 5 & $3 \mathrm{~h}$ & n.r. & / \\
\hline 3 & $\mathrm{InCl}_{3} / \mathrm{TMSCl}$ & $0.1 / 5$ & $25 \min$ & $63 \%$ & $70: 30$ \\
\hline 4 & $\mathrm{InCl}_{3} / \mathrm{TMSCl}$ & $0.05 / 2.5$ & $35 \mathrm{~min}$ & $81 \%$ & $67: 33$ \\
\hline 5 & $\mathrm{InCl}_{3} / \mathrm{TMSCl}$ & $0.01 / 2$ & $3 \mathrm{~h}$ & $61 \%$ & $80: 20$ \\
\hline
\end{tabular}

$6 \quad \mathrm{InCl}_{3} / \mathrm{TMSCl} \quad 0.005 / 2 \quad 13 \mathrm{~h} \quad 64 \% \quad 80: 20$

${ }^{[\mathrm{a}]}$ Isolated yield.

${ }^{[b]}$ Diastereomeric ratios were determined by ${ }^{1} \mathrm{H}$ NMR.

In parallel to our studies of $\mathrm{InCl}_{3} / \mathrm{TMSCl}$ as a potent mild Lewis acid system, rare-earth metal triflates or more generally metallic triflate of type "M(OTf $)_{3}$ " were also promising species since they were reported in catalytic version of Mukaiyama aldol reaction but also for Sakurai allylation. ${ }^{[10]}$ Thus, with these elements in hands, an investigation of metallic triflate was also conducted on peroxyacetal 3a in a Sakurai reaction with allytrimethylsilane $\mathbf{5}$.

Post-transition metal triflates such as indium(III) or bismuth(III) revealed to be poorly effective as Lewis acid in our reaction (Table 2, entries 1 and 2). In particular, bismuth(III) led to the formation of many degradation products in a very short time, while reactions employing $\mathrm{In}(\mathrm{OTf})_{3}$ proceeded slowly and extended reaction times brought many side-products without improving the yield of dioxolane 4a. Some popular rare-earth metal triflates in catalysis were also screened at $10 \%$ mol. ${ }^{[10 a]}$ Reaction employing triflates of $\mathrm{Yb}(\mathrm{III}), \mathrm{Y}(\mathrm{III})$, and $\mathrm{La}(\mathrm{III})$ proceeded very slowly $(6-48 \mathrm{~h})$ giving modest yields of compound 4a, resulting again in a bad conversion/ degradation ratio (Table 2, entries 5,6 and 7). In contrast, scandium(III) gave interesting results, comparable to those obtained with $\mathrm{InCl}_{3} / \mathrm{TMSCl}$ (Table 2, entry 3). Decreasing the amount of catalyst by half did not modify the results (Table 2, entry 4 ). The improved reactivity of $\mathrm{Sc}(\mathrm{OTf})_{3}$ towards other tested metal rare-earth triflates is not surprising since $\mathrm{Sc}(\mathrm{OTf})_{3}$ is known to possess a higher oxophilicity. ${ }^{[1]}$

Table 2. Sakurai reaction study with various metal (III) triflates as catalyst on peroxyacetal $\mathbf{3 a}$.

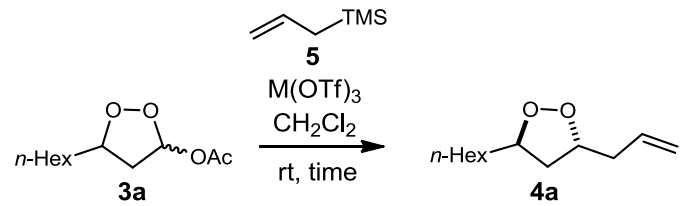

\begin{tabular}{|c|c|c|c|c|c|}
\hline Entry $^{[\mathrm{a}]}$ & Conditions & $\begin{array}{l}\text { Stoichio- } \\
\text { metry } \\
\text { (equiv) }\end{array}$ & $\begin{array}{l}\text { Reaction } \\
\text { Time }\end{array}$ & Yield $^{[\mathrm{a}]}$ & $\begin{array}{c}\mathrm{dr}^{[\mathrm{b}]} \\
\text { trans:cis }\end{array}$ \\
\hline 1 & $\mathrm{Bi}(\mathrm{OTf})_{3}$ & 0.1 & $30 \mathrm{~min}$ & $21 \%$ & $80: 20$ \\
\hline 2 & $\operatorname{In}(\mathrm{OTf})_{3}$ & 0.1 & $60 \mathrm{~min}$ & $31 \%$ & $68: 32$ \\
\hline 3 & $\mathrm{Sc}(\mathrm{OTf})_{3}$ & 0.1 & $30 \mathrm{~min}$ & $82 \%$ & $67: 33$ \\
\hline 4 & $\mathrm{Sc}(\mathrm{OTf})_{3}$ & 0.05 & $30 \mathrm{~min}$ & $78 \%$ & $67: 33$ \\
\hline 5 & $\mathrm{Yb}(\mathrm{OTf})_{3}$ & 0.1 & $6 \mathrm{~h}$ & $49 \%$ & $83: 17$ \\
\hline 6 & $\mathrm{Y}(\mathrm{OTf})_{3}$ & 0.1 & $48 \mathrm{~h}$ & $34 \%$ & $86: 14$ \\
\hline 7 & $\mathrm{La}(\mathrm{OTf})_{3}$ & 0.1 & $19 \mathrm{~h}$ & $31 \%$ & $78: 22$ \\
\hline
\end{tabular}

${ }^{[\mathrm{a}]}$ Isolated yield.

${ }^{[b]}$ Diastereomeric ratios were determined by ${ }^{1} \mathrm{H}$ NMR.

Because $\mathrm{InCl}_{3} / \mathrm{TMSCl}$ and $\mathrm{Sc}(\mathrm{OTf})_{3}$ exhibited similar results in term of reaction time, catalyst loading, diastereoselectivities and yields, we chose to 
further study these two catalytic systems under the optimized selected conditions (Table 1, entry 4 and Table 2, entry 4). The influence of lateral chain $R^{1}$ at position 3 of 1,2-dioxolanyl acetates $3 \mathbf{b}$-g was investigated in the Sakurai reaction with allylTMS (Table 3). $\quad \mathrm{InCl}_{3} / \mathrm{TMSCl}$ and $\mathrm{Sc}(\mathrm{OTf})_{3}$ behaved similarly to furnish 1,2-dioxolanes $\mathbf{4 b - g}$, giving same selectivity. Only some differences appeared on the yield with sometimes a significant improvement with $\mathrm{InCl}_{3} / \mathrm{TMSCl}$ compared to $\mathrm{Sc}(\mathrm{OTf})_{3}$ (Table 3, Entries 1 and 7).

When these results are compared to our previous report involving $\mathrm{SnCl}_{4}$ or $\mathrm{TiCl}_{4}$ as Lewis acids, ${ }^{[3]}$ these two catalytic systems gave overall slightly lower yields than sub-stoichiometric $\mathrm{SnCl}_{4}$ but it was compensated by a higher selectivity toward trans product.

Table 3. Sakurai reaction with $\mathrm{InCl}_{3} / \mathrm{TMSCl}$ or $\mathrm{Sc}(\mathrm{OTf})_{3}$ as catalysts on different substrates $\mathbf{3 b}$-g.
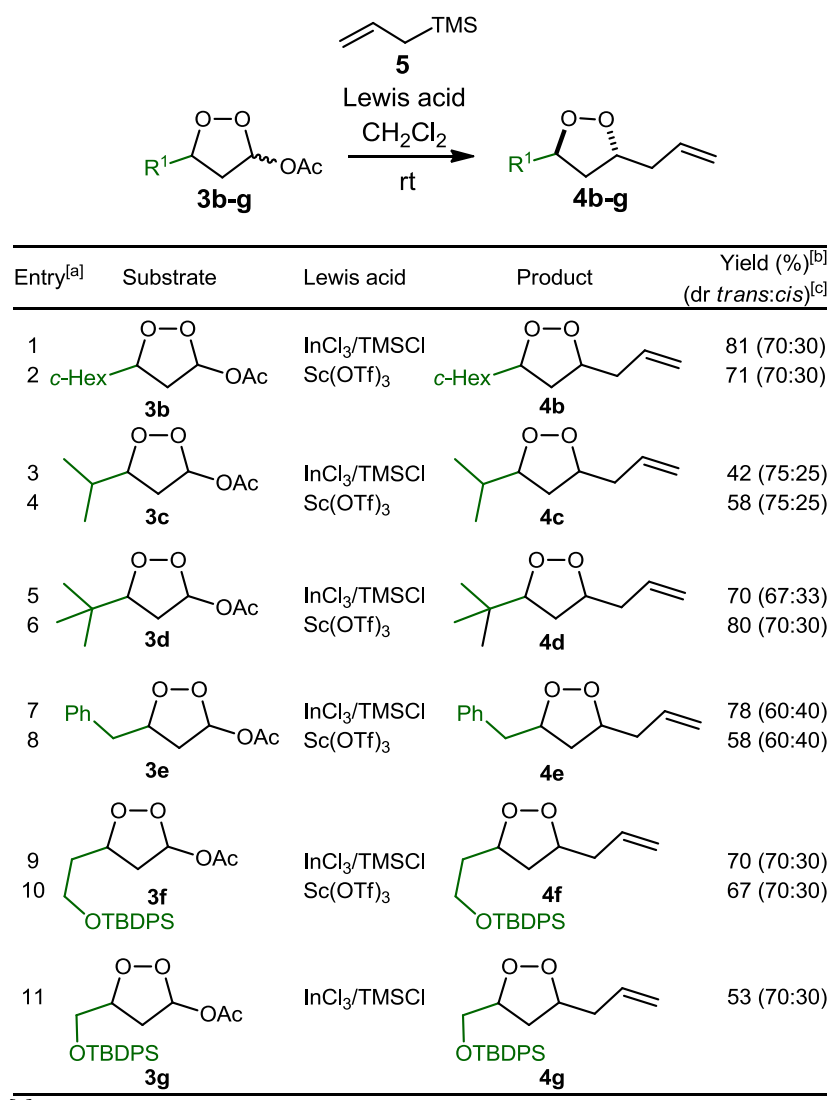

${ }^{[a]}$ Reaction conditions: 3a ( 1 equiv.), $\mathrm{InCl}_{3} / \mathrm{TMSCl}(5 / 250$ mol\%) or $\mathrm{Sc}(\mathrm{OTf})_{3}(5 \mathrm{~mol} \%)$, AllylTMS 5 (3 equiv.), 30$60 \mathrm{~min}$.

${ }^{[b]}$ Isolated yield.

${ }^{[c]}$ Diastereomeric ratios were determined by ${ }^{1} \mathrm{H}$ NMR.

The nature of the nucleophile was also examined on dioxolanyl acetate $\mathbf{3 a}$ for the two selected catalysts (Table 4). Methyl allyltrimethylsilane 6 gave product 15 with similar results for both systems (Table 4, entries 1-2), as well as TMS cyanide 7 and TMS azide 8 (Table 4, entries 3-4 and 5-6), which produced very efficiently compounds $\mathbf{1 6}$ and $\mathbf{1 7}$. Triethylsilane 9 was able to reduce the acetal function giving dioxolane 18, but the yield was significantly higher with $\mathrm{Sc}(\mathrm{OTf})_{3}$ (Table 4, entries 7-8). Mukaiyama aldol reaction was also experienced under our two selected conditions. Ketone derivatives gave contrasted results; enol ether $\mathbf{1 0}$ from acetophenone gave good conversion in compound $\mathbf{1 9}$, in particular with $\mathrm{Sc}(\mathrm{OTf})_{3}$ (entry 10) but $t$-butyl methyketone derivative $\mathbf{1 1}$ reacted sluggishly giving poor yields (until $28 \mathrm{~h}$ ) of $t$-butyl ketone $\mathbf{2 0}$ in both cases (Table 4, entries 11-12); this poor yield could be attributed to some steric hindrance in the nucleophile. Silyl enol ether of esters and thioesters proved to react similarly under the two tested conditions affording ester $\mathbf{2 1}$, thioesters $\mathbf{2 2}$ and $\mathbf{2 3}$ in nice yields (Table 4, entries 13-18). Thioesters 22 and $\mathbf{2 3}$ are particularly interesting, since some cross coupling reactions could be applied ${ }^{[12]}$ and because of their ease of conversion into the corresponding carboxylic acid. For example, we were able to convert thioester $\mathbf{2 2}$ into the corresponding carboxylic acid 24 with $\mathrm{H}_{2} \mathrm{O}_{2}$ and $\mathrm{LiOH}$ in aqueous THF in $1 \mathrm{~h}$ at $\mathrm{rt}$ in $99 \%$ yield.

Table 4. Addition of various nucleophiles to peroxyacetal $\mathbf{3 a}^{[a]}$ under catalytic conditions.

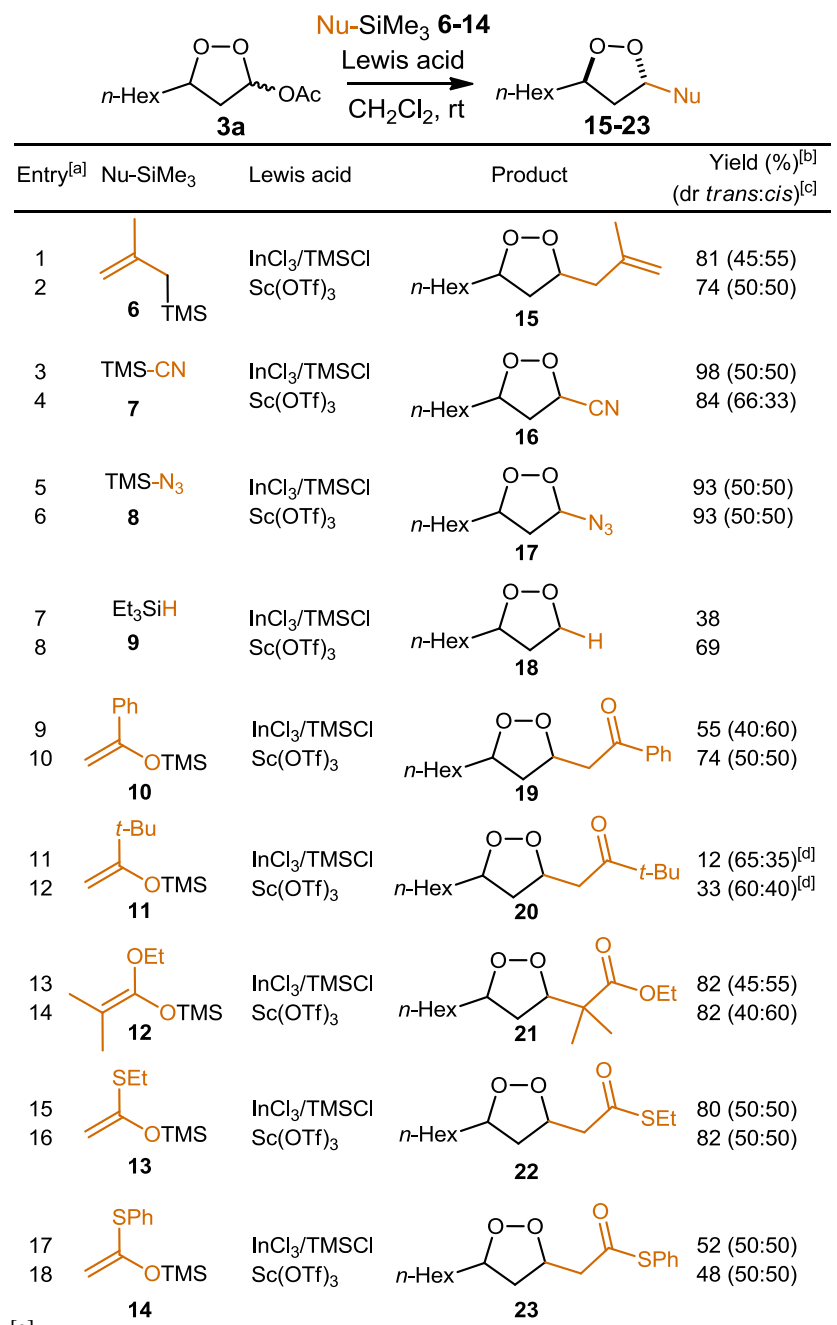

${ }^{\text {[a] }}$ Reaction conditions: 3a ( 1 equiv.), $\mathrm{InCl}_{3} / \mathrm{TMSCl}$ (5/250 $\mathrm{mol} \%)$ or $\mathrm{Sc}(\mathrm{OTf})_{3}(5 \mathrm{~mol} \%)$, nucleophile 6-14 (3 equiv.), 30-60 min.

${ }^{[\mathrm{b}]}$ Isolated yield. 
${ }^{[c]}$ Diastereomeric ratios were determined by ${ }^{1} \mathrm{H}$ NMR.

[d] $20 \mathrm{~h}$ and $28 \mathrm{~h}$ reaction time using respectively $\mathrm{InCl}_{3} / \mathrm{TMSCl}$ and $\mathrm{Sc}(\mathrm{OTf})_{3}$.

When these results are now compared to the substoichiometric utilization of $\mathrm{SnCl}_{4}$ as a Lewis acid, ${ }^{[3]}$ it can be observed that the yields were overall similar and diastereoselectivities were slightly better towards trans products by using the catalytic versions. Nevertheless, there are some exceptions where strong Lewis acids are superior, such as with $t$-butyl enol ether 11, which seemed to react better with $\mathrm{SnCl}_{4}$ due to higher reactivity of this later. ${ }^{[3]}$ For the same reason 1-bromo- and 1-chloro-trimethylsilanes were completely inert by using our selected catalytic systems due to a decreased nucleophilicity of these allylsilanes. In contrast, $\mathrm{InCl}_{3} / \mathrm{TMSCl}$ and $\mathrm{Sc}(\mathrm{OTf})_{3}$ were far superior to $\mathrm{SnCl}_{4}$ (and $\mathrm{TiCl}_{4}$ ) in some cases. TMSCN 7 and $\mathrm{TMSN}_{3} \mathbf{8}$ gave significant higher yields with both catalytic systems. More importantly, enol ether of ester 12 and thioesters 13 and 14 were completely unreactive with $\mathrm{SnCl}_{4}$ and $\mathrm{TiCl}_{4}$, whereas compounds 21, 22, 23 were very efficiently obtained with the catalytic methods, expanding the initial scope of our reaction.

In conclusion, we developed a new catalytic protocol of functionalization for 1,2-dioxolanyl acetates, identifying two efficient systems, namely $\mathrm{InCl}_{3} / \mathrm{TMSCl}$ and $\mathrm{Sc}(\mathrm{OTf})_{3}$. Overall the use of $\mathrm{InCl}_{3} / \mathrm{TMSCl}$ or $\mathrm{Sc}(\mathrm{OTf})_{3}$ over $\mathrm{SnCl}_{4}$ (and $\mathrm{TiCl}_{4}$ ) is justified by simpler experimental procedures (room temperature versus $-40^{\circ} \mathrm{C}$, inert powders versus fumigating and hazardous reagents), atom economy and improvement of diastereoselectivity. Although some poorly reactive species such as deactivated allylsilanes, and hindered nucleophiles work better with $\mathrm{SnCl}_{4}$ and $\mathrm{TiCl}_{4}$, the two new catalytic systems also enlarge the reagents scope to ester and thioester enol ether derivatives, which makes complementary the catalytic and the stoichiometric versions of the studied transformation.

\section{Experimental Section}

\section{General Procedure for the preparation of peroxy- hemiacetals 2a-g:}

To a solution of cyclopropanol $\mathbf{1 a - g}$ ( 1 equiv.) in THF (1 $\mathrm{mL} / \mathrm{mmol})$, was added $\mathrm{Mn}(\mathrm{acac})_{3}(0.5 \mathrm{~mol} \%)$ and the reaction mixture was then stirred under an atmosphere of oxygen. After disappearance of starting material monitored on TLC (usually from 1 to $2 \mathrm{~h}$ ), pentane was added precipitating most of the manganese salts. The solution was filtrated on a silica pad and was rinsed with $\mathrm{Et}_{2} \mathrm{O}$ several times. Volatiles were removed under reduced pressure without heating to afford peroxy-hemiacetals $\mathbf{2 a}$ g. This procedure allows generally excellent yields with sufficiently pure materials for further utilization. In some cases, flash column chromatography might be needed, we advise to perform it in isocratic gradient as fast as possible.

General Procedure for the preparation of acetoxyendoperoxyacetal 3a-g:
To an ice-bath cooled solution of peroxy-hemiacetal $\mathbf{2 a - g}$ (1 equiv.) in anhydride acetic $(2 \mathrm{~mL} / \mathrm{mmol})$ was added $\mathrm{Yb}(\mathrm{OTf})_{3}(10 \mathrm{~mol} \%$, but it can be lower to $0.5 \mathrm{~mol} \%$ such as with 3a; most rare-earth metal triflates are usable with similar results in this reaction). Reaction was monitored by TLC and when no starting material remains (usually 30 min-1 $\mathrm{h}$ ) the reaction was quenched by pouring the reaction mixture into a saturated solution of $\mathrm{NaHCO}_{3}$ at 0 $5{ }^{\circ} \mathrm{C}$ to be stirred $30 \mathrm{~min}$ at this temperature. The aqueous phase was extracted with $\mathrm{Et}_{2} \mathrm{O}$ three times and organic layer was washed with brine and dried over $\mathrm{MgSO}_{4}$ Volatiles were removed under reduced pressure without heating, and the residue was used in its state without further purification in case of good purity. When necessary, the residue could be purified on a silica gel flash column chromatography.

General Procedures for the preparation of functionalized 1,2-dioxolanes 4a-g and 15-23 under catalytic conditions:

Prior to use, catalysts were dried (if soggy or old), under high vacuum $(0.5 \mathrm{mmHg})$ and gentle warming with a heatgun.

Using InCl $_{3}$ and TMSCl: To a solution of acetoxyendoperoxyacetal 3a-g (1 equiv.) and desired nucleophile (3 equiv.) in dry DCM $(4 \mathrm{~mL} / \mathrm{mmol})$ was added $5 \mathrm{~mol} \% \mathrm{InCl}_{3}$ and TMSCl (2.5 equiv.) sequentially. After disappearance of starting material monitored on TLC (usually $1 \mathrm{~h}$ ), the reaction mixture was poured into a saturated solution of $\mathrm{NaHCO}_{3}$. Aqueous phase was extracted with $\mathrm{Et}_{2} \mathrm{O}$ three times and organic layer was washed with brine and dried over $\mathrm{MgSO}_{4}$. Volatiles were removed under reduced pressure and the crude residue was purified by silica gel flash column chromatography to afford the different 3,5-disubstituted 1,2 dioxolanes 4a-g and 15-23.

Using Sc(OTf) $)_{3}$ : To a solution of acetoxyendoperoxyacetal 3a-g (1 equiv.) and desired nucleophile (1.5-3 equiv.) in dry DCM $(4 \mathrm{~mL} / \mathrm{mmol})$ was added $5 \mathrm{~mol} \% \mathrm{Sc}(\mathrm{OTf})_{3}$ After disappearance of starting material monitored on TLC (usually $1 \mathrm{~h}$ ), the reaction mixture was poured into a saturated solution of $\mathrm{NaHCO}_{3}$. Aqueous phase was extracted with $\mathrm{Et}_{2} \mathrm{O}$ three times and organic layer was washed with brine and dried over $\mathrm{MgSO}_{4}$. Volatiles were removed under reduced pressure and the crude residue was purified by silica gel flash column chromatography to afford the different 3,5-disubstituted 1,2 dioxolanes $\mathbf{4 a - g}$ and 15-23.

\section{Acknowledgements}

A.P. thanks the MESRI for a PhD fellowship. We thank Karine Leblanc and Jean-Christophe Jullian (BioCIS, ChâtenayMalabry) for HRMS analysis and NMR services, respectively.

\section{References}

[1] a) J. J. Scott, D.-C. Oh, M. C. Yuceer, K. D. Klepzig, J. Clardy, C. R. Currie Science, 2008, 322, 63; b) D.-C. Oh, J. J. Scott, C. R. Currie, J. Clardy Org. Lett. 2009, 11, 633-636.

[2] T. L. Nguyen, L. Ferrié, B. Figadère Tetrahedron Lett. 2016, 57, 5286-5289.

[3] A. Pinet, T. L. Nguyen, G. Bernadat, B. Figadère, L. Ferrié Org. Lett. 2019, 21, 4729-4733.

[4] a) P. H. Dussault, X. Liu Org. Lett. 1999, 1, 13911393; b) P. H. Dussault, I. Q. Lee, H.-J Lee., R. J Lee, 
Q. J. Niu, J. A. Schultz, U. R Zope J. Org. Chem. 2000, 65, 8407-8414; c) P. H. Dussault, H.-J. Lee, X. Liu J. Chem. Soc., Perkin Trans. 2000, 1, 3006-3013; d) A. Ramirez, K. A. Woerpel Org. Lett. 2005, 7, 4617-4620; e) P. Dai, T. K. Trullinger, X. Liu, P. H. Dussault $J$. Org. Chem. 2006, 71, 2283-2292. f) D. C. Martyn, A. P. Ramirez, M. J. Beattie, J. F. Cortese, V. Patel, M. A. Rush, K. A. Woerpel, J. Clardy, Bioorg. Med. Chem. Lett. 2008, 18, 6521-6524.

[5] J. K. Cha, O. G. Kulinkovich Org. React. 2012, 77, 1159.

[6] a) D. Montgomery, K. Reynolds, P. Stevenson J. Chem. Soc., Chem. Commun. 1993, 363-364; b) C. Toratsu, T. Fujii, T. Suzuki, K. Takai Angew. Chem. Int. Ed. 2000, 39, 2725-2727.

[7] a) D. H. Gibson, C. H. DePuy, Tetrahedron Lett. 1969, 10, 2203-2206. b) M. Kirihara, S. Takizawa, T. Momose Chem. Commun. 1998, 16, 1691-1692; c) V. Morisson, J.-P. Barnier, L. Blanco Tetrahedron Lett. 1999, 40, 4045-4046; d) V. Morisson, J.-P. Barnier, L. Blanco Synth. Commun. 2001, 31, 349-357. e) O. G. Kulinkovich, D. A. Astashko, V. I. Tyvorskii, N. A. Ilyina Synthesis 2001, 1453-1455; f) M. Kirihara, H. Kakuda, M. Ichinose, Y. Ochiai, S. Takizawa, A. Mokuya, K. Okubo, A. Hatano, M. Shiro Tetrahedron 2005, 61, 4831-4839; g) W.-B Han, S.-G. Li, X.-W. Lu, Y. Wu Eur. J. Org. Chem. 2014, 3841-3846; h) G.
Z. Elek, V. Borovkov, M. Lopp, D. G. Kananovich Org. Lett. 2017, 19, 3544-3547.

[8] a) K. Ishihara, M. Kubota, H. Kurihara, H. Yamamoto J. Am. Chem. Soc. 1995, 117, 6639-6639; b) K. Ishihara, M. Kubota, H. Kurihara, H. Yamamoto $J$. Org. Chem. 1996, 61, 4560-4567.

[9] a) P. H. Lee, K. Lee, S.-Y. Sung, S. Chang J. Org. Chem. 2001, 66, 8646-8649; b) Y. Onishi, T. Ito, M. Yasuda, A. Baba Eur. J. Org. Chem. 2002, 67, 15781581; c) Y. Onishi, T. Ito, M. Yasuda, A. Baba Tetrahedron 2002, 58, 8227-8235.

[10] a) S. Kobayashi, M. Sugiura, H. Kitagawa, W. W.-L. Lam Chem. Rev. 2002, 102, 2227-2302; b) S. Kobayashi, I. Hachiya Tetrahedron Lett. 1992, 33, 1625-1628; c) S. Kobayashi, I. Hachiya, H. Ishitani, M. Araki Synlett 1993, 7, 472-474; d) S. Kobayashi, I. Hachiya J. Org. Chem. 1994, 59, 3590-3596; e) V. K. Aggarwal, G. P. Vennall Tetrahedron Lett. 1996, 37, 3745-3746.

[11] H. Tsuruta, T. Imamoto, K. Yamaguchi Chem. Commun. 1999, 1703-1704.

[12] a) H. Tokuyama, S. Yokoshima, T. Yamashita, T. Fukuyama, Tetrahedron Lett. 1998, 39, 3189-3192; b) H. Prokopcová, C. O. Kappe Angew. Chem. Int. Ed. 2009, 48, 2276-2286. 


\section{UPDATE}

Access to Functionalized 3,5-Disubstituted 1,2Dioxolanes under Mild Conditions through

Indium(III) Chloride/Trimethylsilyl or

Scandium(III) Triflate Catalysis.

Adv. Synth. Catal. Year, Volume, Page - Page

Alexis Pinet, Bruno Figadère and Laurent Ferrié*

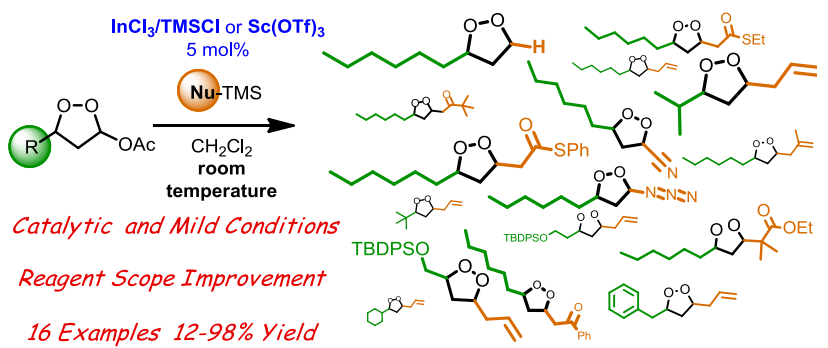

